\title{
Storytelling in preschool: an educational lever for the socio-emotional development of the child
}

\author{
Ihsane DAHANE \\ Mohammed V University in Rabat. Faculty of Educational Sciences
}

\begin{abstract}
Throughout the world, a persistent obsession is carried towards the preschool period, for the simple reason that during this pivotal phase that the child develops gradually, an integrated and simultaneous development touching different aspects, language, cognitive, psychomotor, affective and social...

It is within the preschool institution that the child acquires a solid foundation for facing the world. He is able to assimilate the concepts of solidarity, sharing, socialization, autonomy ... thanks to his many skills; the institution stimulates intellectual effort and artistic creation in children and promotes various skills in them. . In addition, educational practices at school encompass a variety of artistic, Among them is the tale, which constitutes a crucial lever in the development of various skills in preschool children and more particularly the socio-emotional development of the child, as research carried out in this direction emphasizes the need practice exciting activities including storytelling.

Our study examines the effect of storytelling on the socio-emotional development of the child. In this sense, we have developed on the one hand a questionnaire dedicated to educators from schools under the Moroccan Foundation for the Promotion of Preschool Education in the city of

Fez.

The latter focuses on three main areas, namely the representations of educators on the "storytelling" activity, the implementation of this activity, and the value of good practice. . It should be noted that the storytelling activity plays a non-negligible role in the development of the personality, promotes a favorable climate and strengthens the child's self-esteem, through various narrative activities, children gradually learn to recognize the elements of a story and to structure it.
\end{abstract}

Keywords: Preschool Tale -Socio-emotional-practical -development 